\title{
Interdisciplinarietat ciències/matemàtiques a través de les mides a la natura
}

\author{
Víctor López Simó \\ Becari de recerca en formació al CRECIM, UAB \\ victor.lopez@uab.cat
}

L'experiència didàctica que es presenta en aquest article ha estat dissenyada per treballar la interdisciplinarietat entre les ciències $i$ les matemàtiques en la formació inicial del professorat. S'ha dut a terme amb alumnes de la diplomatura d'Educació Primària l'any 2009. L'article comença presentant les lleis d'escala, ja que aquestes seran el model que l'alumne haurà de construir al llarg de la seqüència. Més endavant, s'exposen alguns dels aspectes generals de la seqüència didàctica i l'enfocament que se li ha donat a la interdisciplinarietat entre ciències i matemàtiques. Finalment es presenten algunes de les activitats més rellevants dutes a terme.

Paraules clau: interdisciplinarietat, ciències, matemàtiques, Ileis d'escala, Galileu Galilei, Carl Bergmann, mides a la natura

\section{Les Ileis d'escala}

Les lleis d'escala serveixen per comparar cossos (objectes, sistemes, estructures vives o inerts, etc.) que tenen diferent mida però que es poden considerar semblants des del punt de vista geomètric. Aquestes lleis són molt útils per descriure alguns comportaments no lineals a la natura, especialment quan es comparen diferents cossos als que anomenem "una reproducció a escala l'un de l'altre". La fig. 1 n'il.lustra un exemple concret.

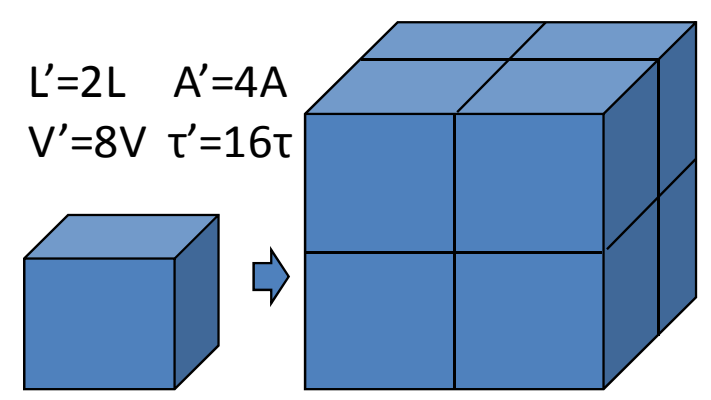

Figura 1. Comparació entre algunes magnituds geomètriques de dos cubs que mantenen una semblança geomètrica amb raó $r=2$.
Els dos cubs que hi apareixen es poden considerar fets a escala l'un de l'altre perquè són geomètricament semblants. Com que el cub de la dreta té totes les arestes el doble de llargues que el cub de l'esquerra, entre ells existeix una raó de semblança (r) igual a dos. Ara bé, algunes de les magnituds físiques que podem mesurar en els cubs no depenen de la longitud, sinó de l'àrea o del volum.

Per exemple, si els dos cubs estan fets del mateix material, el gran no pesarà dues sinó vuit vegades més que el petit. Si comparem l'àrea de les bases dels cubs trobem que una és $r^{2}$ vegades més gran que l'altre; i si ens fixem en el volum dels dos cubs, el cub gran tindrà un volum $r^{3}$ vegades el del petit. És a dir, que al comparar l'àrea i el volum dels dos cubs, els canvis observats no són proporcionals a r, sinó a una potència d'aquesta raó.

Aquestes relacions entre les magnituds dels dos cubs es contraposen a una concepció molt estesa socialment, segons la qual "si el cub de la dreta és el doble de gran, és evident que pesarà el doble que el petit".

En el fons, aquesta afirmació és el resultat d'una concepció espontània segons la qual totes les relacions directes que existeixen a la natura són lineals. 
Hi ha múltiples contextos on s'utilitzen les lleis d'escala, especialment en física d'estructures, en biologia o en arquitectura. Dos dels contextos que poden ser més aplicables en l'ensenyament de les ciències són:

\section{a) La resistència a la fractura de les estructures}

A inicis del s. XVII, Galileu Galilei es preguntava per què no es podien construir vaixells de mida il.limitada. Va arribar a la conclusió que si realment es poguessin construir vaixells tan i tan grans, aquests acabarien trencant-se esclafats pel seu propi pes. Galileu argumentà que l'àrea de les seccions transversals dels elements encarregats de suportar esforços (les bigues dels edificis, els pals dels vaixells, els ossos dels animals, els troncs dels arbres, etc.) influeix en la capacitat que té una estructura de suportar aquests esforços sense trencar-se.

Si una estructura d'aquestes augmentés de mida a escala amb una raó $\mathbf{r}$, la seva capacitat de suportar forces sense trencar-se seria $r^{2}$ vegades més gran perquè aquest és el factor que hauria augmentat la seva àrea. Ara bé, el seu pes hauria augmentat tant com el seu volum, és a dir $\mathbf{r}^{3}$ vegades. Per tant, si un objecte augmentés de mida mantenint una raó de semblança amb la seva forma original, el seu pes estaria creixent més ràpidament que no pas la seva capacitat per suportar-lo (Haldane, 1926).

Aquesta relació entre la mida i la resistència a la fractura es pot observar de manera regular a la natura. Per exemple, mentre que els arbres compten amb una tija lignificada per suportar el seu propi pes, la majoria d'herbes en tenen prou amb tiges carnoses per mantenir-se erigides. En canvi, si poguéssim fer créixer una herba fins assolir la mida d'un arbre la seva tija seria insuficient per suportar el seu propi pes i acabaria fracturant-se. Un altre exemple molt utilitzat per explicar aquesta Ilei d'escala són els insectes. Mentre les formigues poden carregar fins a 50 vegades el seu pes, si existissin formigues gegants com les que el cinema ens té acostumats, les potes d'aquests animals amb prou feines podrien suportar el seu propi pes.

\footnotetext{
b) La resistència als canvis de temperatura dels animals homeoterms

250 anys després dels estudis de Galileu l'alemany Carl Bergmann va analitzar la relació entre la mida de molts ocells i mamífers i el clima on vivien, arribant a establir que els individus de subespècies o races geogràfiques en climes més freds eren més grans i pesants que les dels climes més càlids. Aquesta regularitat de la natura s'anomenà la Regla de Bergmann.
}

Quina relació té aquesta regla amb les lleis d'escala? La quantitat de calor que un cos intercanvia amb el seu entorn està condicionada pel valor total de la superfície de contacte entre el cos i l'entorn. En canvi, l'energia interna (associada a la temperatura) que un cos pot emmagatzemar ve donada, en bona mesura, pel seu volum. Per tant, al comparar dos cossos semblants de diferent mida amb una raó de semblança $\mathbf{r}$, mentre que la capacitat d'intercanviar calor del més gran serà $\mathbf{r}^{2}$ vegades la del petit, la seva capacitat d'emmagatzemar energia interna serà $r^{3}$ vegades major. És a dir, els cossos grans mantenen la temperatura més fàcilment del que ho fan els cossos petits ja que tenen menys superfície de contacte per unitat de volum.

Tot i les nombroses excepcions amb que compta aquesta regla, algunes recerques I'han extrapolat no només per animals homeoterms, sinó també ectoterms (Timofeev, 2001).

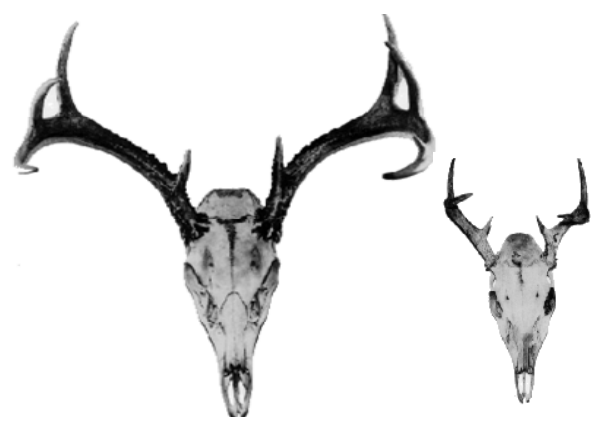

Figura 2. El cérvol de Michigan (esquerra) és significativament més gran que el cérvol de Nicaragua (dreta). La Regla de Bergmann atribueix una relació entre la mida dels individus i el clima on viuen.

\section{Presentació de la unitat didàctica}

La unitat didàctica s'ha implementat durant el curs 2009-2010 al llarg de 12,5 hores repartides en 10 sessions, en les quals s'ha abordat la interdisciplinarietat entre ciències i matemàtiques a través de les lleis d'escala. En aquesta seqüència didàctica les sessions estan repartides de la següent manera:

- Sessió 1: Experiència de mesura, amb diferents tècniques de laboratori, de la massa, la superfície i el volum de diferents peces construïdes amb diferents materials.

- Sessió 2: Taller de càlcul indirecte de la massa i el volum d'edificis emblemàtics a partir de mètodes estimatius: el pes de les columnes gegants de la UAB. 
- Sessió 3: Lectura dels "discursi” de Galileu Galilei en la seva versió adaptada al públic juvenil (Figueiras, 2009).

- Sessió 4: Taller de formulació de la llei d'escala per al cas de la resistència dels cossos a la fractura.

- Sessió 5: Experiència de mesura amb sensors MBL de la temperatura de l'aigua calenta dins de recipients de diferents mides.

- Sessió 6: Taller de formulació de la llei d'escala per al cas de la termoregulació.

- Sessió 7: Elaboració de mapes conceptuals amb un enunciat genèric per a les lleis d'escala.

- Sessió 8: Taller amb software de modelització per treballar les lleis d'escala.

- Sessió 9: Exercicis d'aplicació de les lleis d'escala en diferents contextos.

- Sessió 10: Exercicis d'aplicació de les lleis d'escala en diferents contextos.

Amb aquesta seqüència didàctica es persegueix un doble objectiu:

- El primer objectiu de la unitat didàctica és ajudar els futurs professors a construir un model interpretatiu basat en les lleis d'escala. Per aquest motiu, en les primeres sessions es proposa la realització de diferents prediccions per fomentar l'aparició d'un conflicte entre el model espontani dels alumnes (en el qual la natura sempre té un comportament lineal) i els fets observats: els objectes semblants de diferent mida molt sovint no es comporten de la mateixa manera. Davant d'aquest conflicte cal construir un nou model basat en les lleis d'escala, model que ha de ser útil en un ample ventall de situacions quotidianes, tant a dins com a fora de l'aula. Per tant, a mesura que es construeix el nou model s'utilitzen una varietat de contextos que permeten transferir el coneixement a noves situacions, interpretant tota mena de formes, mides i metabolismes existents a la natura.

- El segon objectiu és ajudar els futurs professors a donar un significat real i profund al concepte d'interdisciplinarietat ciències / matemàtiques. Com donar-hi aquest significat? Per un costat, a través de contextos científics en els que es generi la necessitat d'una interpretació formal utilitzant identitats matemàtiques. D'aquesta manera les matemàtiques apareixen com una eina per descriure i interpretar la natura i els seus patrons de regularitat. Per l'altre costat, utilitzant l'esperit i l'activitat científica (curiositat, voluntat d'interpretar el nostre entorn, creativitat, racionalitat, etc.) com el motor que genera la necessitat de construir identitats, proposar conjectures i arribar a generalitzacions abstractes. En el cas d'aquesta seqüència didàctica, per un costat, es parteix de problemàtiques (com la resistència dels cossos a la fractura o la seva regulació tèrmica) per construir entitats matemàtiques (com la semblança, la raó, la linealitat, les potències, etc.). Al mateix temps, totes aquestes entitats prenen un sentit i un significat en el moment que serveixen per resoldre reptes com ara "per què no podrien existir les formigues gegants?"

Finalment, també es pot analitzar la seqüència des del punt de vista d'un cicle d'aprenentatge (fig. 3). En les primeres sessions es realitzen activitats per explorar el model previ de l'alumnat i s'introdueix una nova problemàtica que acaba portant a estructurar el model de les lleis d'escala en les sessions 7 i 8 . Finalment, les darreres sessions serveixen per aplicar a situacions noves aquest model construït.

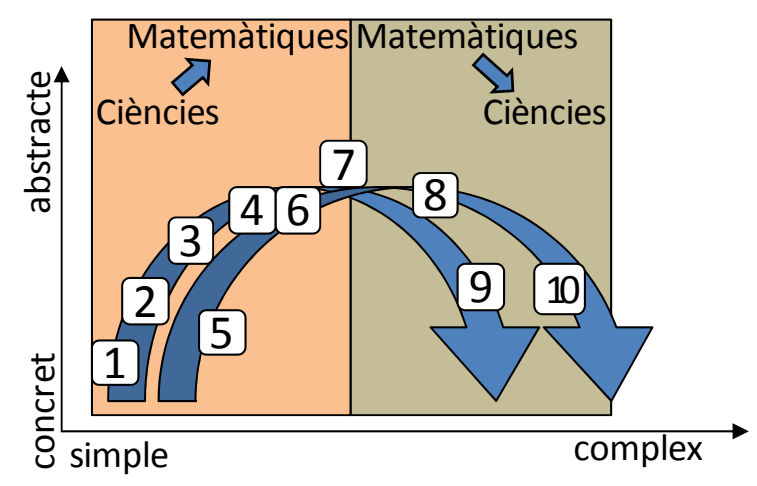

Figura 3. Anàlisi de la seqüència didàctica des del punt de vista d'un cicle d'aprenentatge.

\section{Descripció d'algunes activitats}

A continuació s'exposen breument algunes de les activitats més rellevants dutes a terme al llarg de la seqüència:

\section{El pes de les columnes gegants de la UAB (Sessió 3)}

La Universitat Autònoma de Barcelona compta amb quatre columnes emblemàtiques que mesuren entre 25 i 40 metres d'alçada i que es poden observar des de l'autopista AP-7. Les anomenades columnes d'Alfaro s'utilitzen des de fa anys en diferents activitats educatives de la UAB (inspirada en la proposta de L. Figueiras "Coneixem l'autònoma" (2006), la mesura de l'altura de les columnes 
d'Alfaro és un dels problemes complexos que es realitzen en el Campus Ítaca de la UAB). La nostra activitat consisteix en calcular, a partir de mesures indirectes, l'altura, la massa, l'àrea de la base, el pes i la pressió que exerceix cada columna sobre la seva base. Com que el resultat del càlcul d'aquesta pressió és superior a les 100 tones $/ \mathrm{m}^{2}$, això porta a pensar a molts alumnes que possiblement les columnes siguin buides per dintre, per així no esfondrar-se. Aquest "descobriment" pot arribar a ser sorprenent i estimulant per als alumnes, i tan sols cal comprovar al web de la universitat que, evidentment, no són massisses. Arribats a aquest punt és quan toca preguntar: "quina pressió exerciria sobre la seva base una reproducció a escala de la columna gegant si aquesta mesurés $1 m$ d'altura? També hauria d'estar buida per evitarne l'esfondrament?".

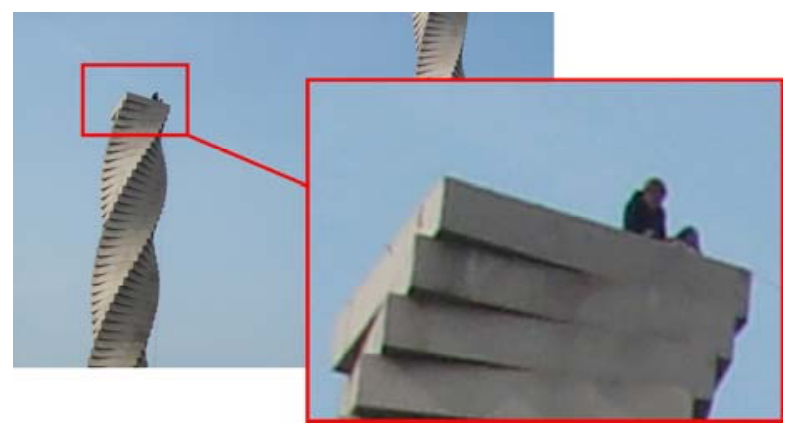

Figura 4. Una imatge com aquesta serveix per estimar la massa de la columna (formada per peces) tenint en compte les dimensions de cada peça, el nombre de peces que hi ha i la densitat del granit.

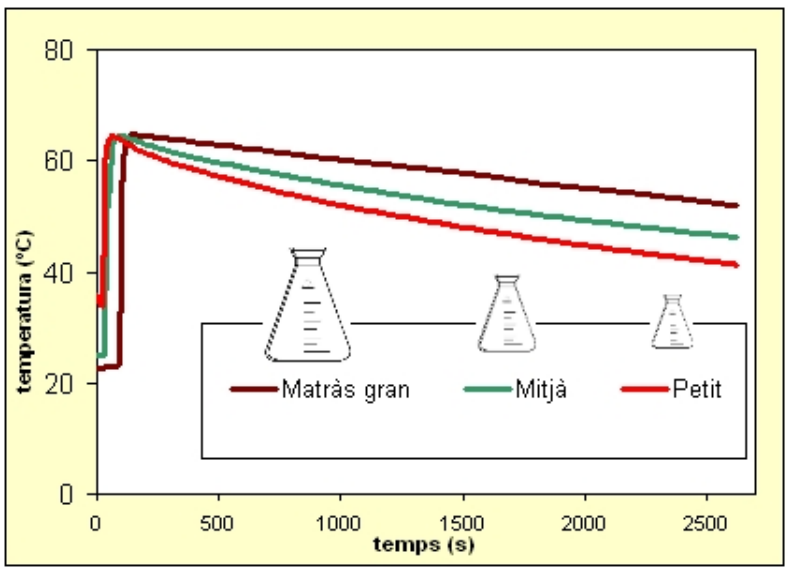

Figura 5. A la gràfica temperatura-temps es pot observar com al cap de 30 minuts hi ha més de 10 ${ }^{\circ} \mathrm{C}$ de diferència entre l'aigua del matràs gran i la del petit.

\section{b) La temperatura de l'aigua calenta dins de recipients de diferent mida (Sessió 5)}

Aquesta experiència de laboratori serveix per estudiar l'evolució de la temperatura de l'aigua calenta (inicialment a uns $65^{\circ} \mathrm{C}$ ) col.locada dins de tres matrassos erlenmeyer de mides diferents (un de gran, un de mitjà $i$ un de petit). Gràcies als sensors MBL es pot enregistrar la temperatura al llarg del temps i observar-ne l'evolució en un ordinador. Al cap de pocs minuts la temperatura del recipient petit decreix molt més ràpidament que la del recipient gran. Aquesta experiència permet contrastar les prediccions inicials dels alumnes, segons les quals la temperatura de refredament és la mateixa en els tres recipients.

\section{c) Elaboració de mapes conceptuals amb un enunciat genèric de les lleis d'escala (Sessió 7)}

"Què tenen en comú la resistència a la fractura $i$ la termoregulació?". Durant les sessions anteriors els alumnes han anat construint enunciats com ara "els animals més grans necessiten ossos més forts per aguantar-se drets" o bé "els animals d'una mateixa espècie es protegeixen millor del fred, entre altres factors, com més grans són", però fins ara són enunciats intuïtius fruit de l'experiència a l'aula o al laboratori. Per posar en comú aquests diferents enunciats cal definir de manera formal entitats matemàtiques (raó, semblança, proporcionalitat lineal i no lineal, etc.) i un cop fet això, passar de la conjectura a la generalització de l'enunciat de les lleis d'escala. Una bona manera de fer-ho és a través d'un mapa conceptual. En aquesta activitat, els alumnes per parelles realitzen un mapa conceptual on apareixen els conceptes claus i les relacions entre si. Posteriorment es posen en comú els diferents mapes i se n'elabora un de conjunt.

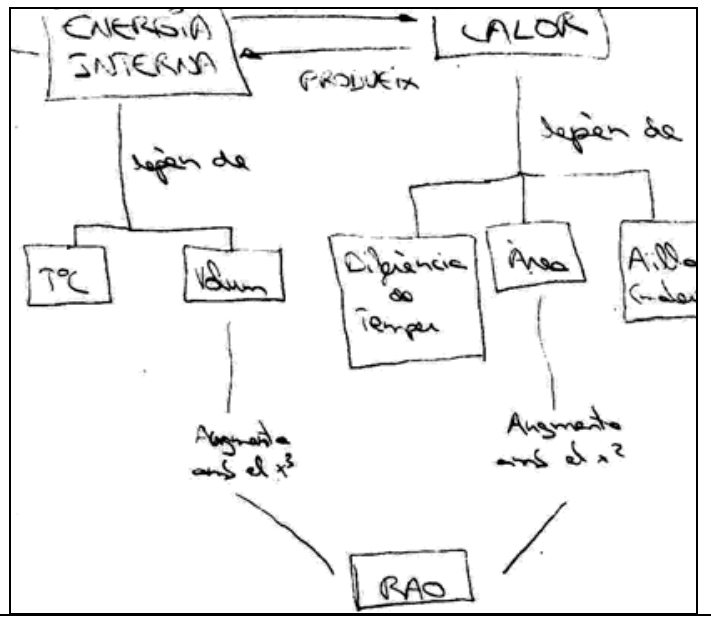

Figura 6. Mapa conceptual de relacions matemàtiques entre variables. 


\section{d) Exercicis d'aplicació de les lleis d'escala en diferents contextos (Sessió 9)}

Les últimes sessions de la seqüència serveixen per transferir el model establert a nous contextos, com ara:

- Per què la forma de les muntanyes és piramidal?

- Com és que les herbes no tenen tronc $\mathrm{i}$ els arbres sí?

- Com haurien de ser els conductes per on circula el líquid termòfor d'un captador fototèrmic?

- Què vol dir que les formigues siguin tan "fortes" o les puces facin salts tan "grans"?

- Com relacionem la regla d'Allen amb la regla de Bergmann?

- Per què trobem als oceans animals més grans que els que podrien viure a terra ferma?

Tot i que respondre aquestes qüestions requereix complexes anàlisis (on intervé un ric entramat de variables fisiològiques, geològiques, arquitectòniques, ecològiques, tecnològiques, etc.) que van molt més enllà de les lleis d'escala, el fet d'explorar una varietat tan gran de contextos permet extreure'n un patró de regularitat.

De fet, es pot observar com la riquesa de les argumentacions i el rigor conceptual amb que els estudiants responen cadascuna d'aquestes qüestions és qualitativament superior al tipus de respostes que es donaven abans de començar la unitat.

\section{Conclusions}

Encara que el contingut d'aquesta seqüència didàctica no està inclòs actualment de manera explícita en cap currículum educatiu, l'estudi de les Ileis d'escala poden arribar a ser de gran utilitat en l'ensenyament de les ciències i les matemàtiques, perquè el seu aprenentatge no només passa per la construcció d'un model interpretatiu dels comportaments i les mides a la natura, sinó que acostuma a anar acompanyat d'una relativa sorpresa i satisfacció intel-lectual en la construcció d'aquest model. A més a més, com s'ha remarcat al llarg de l'article, permet als estudiants (futurs mestres) donar un significat profund a la interdisciplinarietat entre les ciències $i$ les matemàtiques $i$ combinar l'activitat científica (observacions, prediccions, construcció de models interpretatius, etc.) amb l'activitat matemàtica (definicions abstractes, conjectures, generalitzacions, etc.).

\section{BIBLIOGRAFIA}

FIGUEIRAS, L. (2009). Discursos de Galileo Galiei: Resistencia de los cuerpos a la fractura. Madrid: Equipo Sirius.

HALDANE, J. S. B. (1926). On Being the Right Size. Harper's Magazine. Accessible online el novembre del 2010 a http://irl.cs.ucla.edu/papers/right-size.html.

TIMOFEEV, S. F. (2001). Bergmann's Principle and Deep-Water Giantism in Marine Crustaceans. Biology Bulletin, Vol. 28, No. 6, 2001, pp. 646650. 